\title{
Primary dural lymphomas: a review
}

\author{
Fabio M. Iwamoto, M.D., and Lauren E. Abrey, M.D. \\ Department of Neurology, Memorial Sloan-Kettering Cancer Center, New York, New York
}

\begin{abstract}
$\checkmark$ Primary dural lymphoma (PDL) is a rare subtype of primary central nervous system lymphoma (PCNSL) that arises from the dura mater and differs biologically from other CNS lymphomas. The PDL is usually a low-grade marginal zone lymphoma (MZL), whereas other types of PCNSLs are usually high-grade, diffuse, large B-cell lymphomas. A PDL usually presents with single or multiple extraaxial masses that enhance diffusely with addition of contrast material and can be confused with meningioma. The MZLs respond well to local therapy such as surgery and radiation treatment. Most patients attain complete response and have good local disease control. Nevertheless, the risk of systemic relapse appears to be high, probably because the dura mater is outside of the blood-brain barrier.
\end{abstract}

\section{KEY WORDS • primary central nervous system lymphoma • dura mater • non-Hodgkin lymphoma}

$\mathrm{P}$ rimary CNS lymphoma is an extranodal nonHodgkin lymphoma that arises from the brain parenchyma, eyes, meninges, or spinal cord in the absence of systemic disease. ${ }^{4}$ The most common type of PCNSL presents as a space-occupying lesion in the brain parenchyma. Lymphoma arising primarily from the meninges without brain or systemic involvement is rare. Primary leptomeningeal lymphoma arises within the leptomeningeal space and usually presents with headache, meningeal signs, and cranial nerve involvement. ${ }^{25}$ Primary dural lymphoma arises from the dura mater and differs biologically from other CNS lymphomas. ${ }^{9,24}$ It is usually a low-grade B-cell MZL, whereas other types of PCNSL are usually high-grade, diffuse, large B-cell lymphomas. Marginal zone lymphoma is an indolent non-Hodgkin lymphoma that occurs more frequently in the gastrointestinal tract, where it has been called the "mucosa-associated lymphoid tissue (MALT) lymphoma."17 This specific pathological subtype of the non-Hodgkin lymphoma has important therapeutic and prognostic implications, making PDL a distinct subtype of PCNSL.

\section{Epidemiology}

The incidence of PDL is unknown, but it is a rare form of primary intracranial lymphoma. This lesion accounted for $2.4 \%$ of 335 patients with PCNSL in our institution. ${ }^{18}$ Most published cases of PDL are single-patient reports, and of the two largest series of PDL, one had only $15^{38}$ and one had eight ${ }^{18}$ patients. This lesion occurs more often in middle-aged women, in contrast to brain parenchyma PCNSL, which has a slight male predilection. In the two series of PDL mentioned earlier, the female/male ratio was $4: 1$ in one and 3:1 in the other. In contrast with par-

\footnotetext{
Abbreviations used in this paper: $\mathrm{MR}=$ magnetic resonance; MZL = marginal zone lymphoma; PCNSL = primary central nervous system lymphoma; PDL = primary dural lymphoma.
}

enchymal PCNSL, there has been no clear association between acquired and congenital immunosuppression and the development of PDL.

\section{Pathogenesis}

The pathogenesis of PDL is not well understood because the dura is devoid of any lymphoid tissue. One hypothesis is that a benign inflammatory condition of the dura could attract polyclonal lymphocytes from which a monoclonal lymphoma could arise. Chronic infections and autoimmune diseases have been associated with MZL. The most common type of MZL occurs in the stomach and is associated with chronic infection with Helicobacter pylori. ${ }^{17}$ Campylobacter jejuni ${ }^{26}$ and Chlamydia psittaci ${ }^{13}$ probably play a similar role in the pathogenesis of small bowel and ocular adnexal MZL, respectively. Chronic hepatitis $\mathrm{C}$ has been associated with nodal and splenic MZL. ${ }^{7}$ Primary MZL of the dura has not been definitively associated with any infectious or autoimmune disease, but patients with hepatitis $\mathrm{C},{ }^{12}$ scleroderma, ${ }^{29}$ Graves disease, ${ }^{33}$ and Sjögren disease ${ }^{22}$ have been reported.

\section{Clinical Presentation}

Symptoms are usually dependent on the location of the tumor. The most common clinical presentations are headaches, seizures, focal sensory or motor deficits, and visual disturbances. ${ }^{18}$ Other described symptoms include nausea, vomiting, and ataxia. ${ }^{38}$ More rarely reported presentations include progressive cranial nerve dysfunction causing bilateral visual and hearing loss due to progressive dural involvement by MZL. ${ }^{12}$ Another unusual presentation was reported in a patient who had headaches and acute hemiparesis mimicking an acute subdural hematoma. ${ }^{15}$ In patients with PDL arising in the spinal cord dura, radicular pain and paraparesis are the most common presenting symptoms. ${ }^{30}$ 

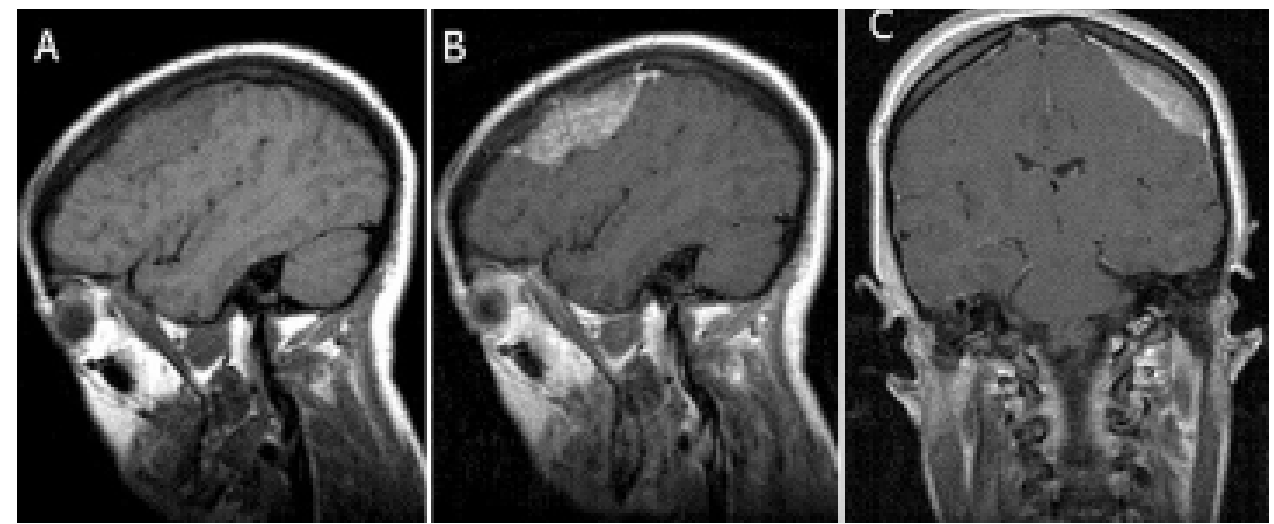

FIG. 1. Brain MR images demonstrating a left frontal hypointense extraaxial mass on a $T_{1}$-weighted sagittal view (A); the tumor enhances diffusely after gadolinium injection (B). On a coronal $\mathrm{T}_{1}$-weighted MR image obtained after injection of gadolinium (C), a dural tail tumor is evident.

\section{Neuroimaging}

Magnetic resonance imaging reveals single or multiple extraaxial masses that enhanced diffusely after administration of gadolinium contrast (Fig. 1). Up to $50 \%$ of patients in one series had more than one mass. ${ }^{18}$ The cerebral convexities are the most common site, but the falx, tentorium, and sellar/parasellar regions can also be involved. ${ }^{38}$ More rarely, intraventricular ${ }^{18,23}$ and spine ${ }^{30}$ masses can occur. Other MR imaging findings include en plaque thickening of the meninges, dural tail sign, underlying parenchymal vasogenic edema, early invasion of the underlying brain, calvarial hyperostosis, and bone erosion.

\section{Differential Diagnosis}

Unquestionably, the most important differential diagnosis is meningioma. In a series of 15 patients with PDL, a clinical and radiographic diagnosis of meningioma was made in 14 prior to the pathological diagnosis. ${ }^{38}$ The PDLs and meningiomas share many features, including higher incidence in women, similar age of onset (Table 1), and frequent occurrence of more than one extraaxial lesion. Neuroimaging findings are also similar; both tumors present with extraaxial lesions that appear iso- or hypointense on $\mathrm{T}_{1}$-weighted MR images and diffusely enhance with administration of gadolinium. Moreover, a dural tail is a frequent finding in both meningiomas and PDL. ${ }^{38}$ On the other hand, underlying vasogenic edema appears to be more common in PDL.

Other differential diagnoses include dural metastasis, solitary fibrous tumors, gliosarcomas, leiomyosarcomas, hemangiopericytomas, melanocytomas, plasmacytomas, inflammatory pseudotumors, neurosarcoidosis, plasma cell granulomas, Rosai-Dorfman disease, Castleman disease, xanthomas, rheumatoid nodules, and tuberculomas. ${ }^{21}$

\section{Pathological Findings}

In patients with PDL, the most frequent histopathological diagnosis is MZL (Table 1). Very rarely, cases of highgrade non-Hodgkin lymphoma, ${ }^{2,30}$ low-grade follicular lymphoma ${ }^{10}$ and Hodgkin disease ${ }^{20}$ have been reported.

The pathological features of MZL arising in the dura are similar to MZL in other extranodal sites. ${ }^{39,40}$ This tumor has a predominance of small B-cell lymphocytes, but plasma cells, monocytoid-appearing lymphocytes, and scattered large lymphocytes can also be present. ${ }^{17}$ The B cells of this type of lymphoma share the cytological features and immunophenotype of marginal zone B cells, and MZL is also characterized by negative markers for CD10, CD5, and CD23. ${ }^{17}$

\section{Staging Evaluation}

Neurological staging is of primary importance. This includes an MR image of the brain and/or spine (depending on the symptoms and signs) with gadolinium or, if MR imaging is contraindicated, a computed tomography scan with contrast material. Involvement of the leptomeningeal space due to direct tumor contiguity is common and occurred in $63 \%$ of patients with PDL in one series. ${ }^{18}$ Consequently, all patients should undergo a lumbar puncture for cytological evaluation of the cerebrospinal fluid unless it is contraindicated. Other cerebrospinal fluid studies that may be helpful include protein, cell count, $\beta_{2}$-microglobulin, immunoglobulin $H$ gene rearrangement, and flow cytometry. ${ }^{3}$

Patients with presumed PDL need to undergo an evaluation to exclude systemic involvement. Although it is typically considered a localized tumor, more than $25 \%$ of patients with nongastric MZL presented with Stage IV disease..$^{40}$ A computed tomography scan of the chest, abdomen, and pelvis, and a bone marrow biopsy sampling with aspirate are the recommended staging procedures.

\section{Prognosis}

A PDL is more indolent and has a better prognosis than parenchymal PCNSL or systemic lymphoma with CNS metastasis. However, further studies with longer clinical follow up are necessary to assess the final outcome in these patients. In general, patients with MZL have a favorable outcome, with a 5-year overall survival rate greater than $86 \%$, without significant differences between gastrointestinal and nongastrointestinal and between localized and disseminated disease. ${ }^{35,36,40}$ 
TABLE 1

Literature review of 56 reported cases of $P D L^{*}$

\begin{tabular}{|c|c|c|c|c|}
\hline Authors \& Year & Age (yrs), Sex & Lymphoma Histology & Treatment & Outcome \\
\hline Nguyen \& Nathwani, 1989 & $74, \mathrm{M}$ & small lymphocytic & resection, $\mathrm{RT}$ & NED, $1.2 \mathrm{yrs}$ \\
\hline Scott, et al., 1990 & $21, \mathrm{~F}$ & NA & IT MTX, RT & NED, 1.8 yrs \\
\hline \multirow{3}{*}{ Miranda, et al., 1996} & $51, \mathrm{~F}$ & small lymphocytic & resection, RT & alive, $1.2 \mathrm{yrs}$ \\
\hline & $46, \mathrm{~F}$ & DLBCL & laminectomy, RT, CHOP, MTX & alive, 1.1 yrs \\
\hline & $53, \mathrm{M}$ & small lymphocytic & laminectomy, RT, IT MTX, cytarabine & alive, $1 \mathrm{yr}$ \\
\hline \multirow{4}{*}{ Kumar, et al., 1997} & $62, \mathrm{~F}$ & MZL & fludarabine & NED, 1.8 yrs \\
\hline & $52, \mathrm{~F}$ & MZL & cytarabine, MTX, IT MTX, RT & NED, $0.6 \mathrm{yr}$ \\
\hline & $43, \mathrm{~F}$ & MZL & RT & NED, $0.7 \mathrm{yr}$ \\
\hline & $57, \mathrm{~F}$ & MZL & RT & NED, $1.2 \mathrm{yrs}$ \\
\hline \multirow{2}{*}{ Kambham, et al., 1998} & $39, \mathrm{~F}$ & MZL & resection & NA \\
\hline & $62, \mathrm{~F}$ & MZL & resection, RT & NA \\
\hline Freudenstein, et al., 2000 & $50, \mathrm{~F}$ & centroblastic/centrocytic & resection, MTX, RT & NED, 3 yrs \\
\hline Johnson, et al., 2000 & $55, \mathrm{~F}$ & Hodgkin disease & resection, $\mathrm{RT}$ & NED, $0.7 \mathrm{yr}$ \\
\hline Sanjeevi, et al., 2001 & $46, \mathrm{~F}$ & MZL & resection, $\mathrm{RT}$ & NED, $1.3 \mathrm{yrs}$ \\
\hline Estevez, et al., 2002 & $70, \mathrm{~F}$ & MZL & RT & NA \\
\hline Goetz, et al., 2002 & $64, \mathrm{~F}$ & MZL & resection, RT & NA \\
\hline Lehman, et al., 2002 & $63, \mathrm{~F}$ & MZL & RT & stable disease \\
\hline \multirow{2}{*}{ Benouaich, et al., 2003} & $38, \mathrm{~F}$ & MZL & resection, IT MTX, RT & NED, 2 yrs \\
\hline & $45, \mathrm{~F}$ & MZL & ifosfamide, doxorubicin, MTX & NED, 1 yr \\
\hline Beriwal, et al., 2003 & $67, \mathrm{~F}$ & follicular & resection, RT & NED, $1.5 \mathrm{yrs}$ \\
\hline Bodi, et al., 2003 & $56, \mathrm{~F}$ & MZL & resection & NED, $1.5 \mathrm{yrs}$ \\
\hline Miller, et al., 2004 & $49, \mathrm{~F}$ & MZL & resection, $\mathrm{CHOP}, \mathrm{RT}$ & NED, $0.5 \mathrm{yr}$ \\
\hline Rottnek, et al., 2004† & $47, \mathrm{M}$ & MZL & resection, $\mathrm{RT}$ & NED, 2.3 yrs \\
\hline & $68, \mathrm{~F}$ & MZL & NA & NA \\
\hline & $29, \mathrm{~F}$ & MZL & RT & NED, 3 yrs \\
\hline & $61, \mathrm{~F}$ & MZL & NA & NED, $1.7 \mathrm{yrs}$ \\
\hline & $62, \mathrm{~F}$ & MZL & RT & NED, $2.1 \mathrm{yrs}$ \\
\hline & $47, \mathrm{M}$ & MZL & NA & NA \\
\hline & $57, \mathrm{~F}$ & MZL & $\begin{array}{l}\text { MTX, vincristine, procarbazine, } \\
\text { cytarabine, RT }\end{array}$ & NED, 5.5 yrs \\
\hline & $70, \mathrm{~F}$ & MZL & RT & NED, 3.9 yrs \\
\hline & $59, \mathrm{~F}$ & MZL & RT & NED, 2.8 yrs \\
\hline & $53, \mathrm{~F}$ & MZL & RT & NED, $0.9 \mathrm{yr}$ \\
\hline & $48, \mathrm{~F}$ & MZL & MTX, RT & NED, 1.7 yrs \\
\hline \multirow[t]{7}{*}{ Iwamoto, et al., 2006} & $64, \mathrm{~F}$ & MZL & $\begin{array}{l}\text { resection, MTX, vincristine } \\
\text { procarbazine, IT MTX } \\
\text { \& cytarabine, RT }\end{array}$ & NED, 6.6 yrs. \\
\hline & $33, \mathrm{~F}$ & MZL & IT MTX, IT cytarabine, RT & NED, 7.2 yrs \\
\hline & $35, \mathrm{M}$ & MZL & $\begin{array}{l}\text { MTX, vincristine, temozolomide, } \\
\text { rituximab, RT }\end{array}$ & NED, 4.5 yrs \\
\hline & $39, \mathrm{~F}$ & MZL & resection, RT & NED, $0.5 \mathrm{yr}$ \\
\hline & $49, \mathrm{~F}$ & MZL & resection, RT & NED, $0.7 \mathrm{yr}$ \\
\hline & $51, \mathrm{~F}$ & MZL & RT & NED, $0.8 \mathrm{yr}$ \\
\hline & $50, \mathrm{~F}$ & MZL & RT & NED, $0.5 \mathrm{yr}$ \\
\hline
\end{tabular}

* $\mathrm{CHOP}=$ cyclophosphamide/doxorubicin/vincristine/prednisolone; $\mathrm{DLBCL}=$ diffuse large B-cell lymphoma; hyper-CVAD = fractionated cyclophos phamide, vincristine, doxorubicin, and dexamethasone; IT = intrathecal, MTX = methotrexate; NA = not available; NED = no evidence of disease; RT = radiation therapy.

$\dagger$ This case was also reported in the series published by Iwamoto, et al. 


\section{Treatment}

Because of the paucity of cases described in the literature, no standard treatment is available for PDL. Clinical Stage $I_{E}$ MZL (extranodal disease limited to a single site) responds favorably to local treatments such as surgery or focal radiation. ${ }^{35,37,40}$ Complete resection of MZL in the dura can be difficult due to multiple tumors, infiltrative behavior, or en plaque presentation. If complete resection is achieved, clinical and radiological follow up with no additional treatment is appropriate. However, for most cases, adjuvant treatment with either radio- or chemotherapy is necessary. Radiotherapy is preferable because MZL is very radiosensitive and requires relatively low doses of radiation; doses as low as 20 Gy have excellent results and minimize the risk of late neurotoxicity. ${ }^{18}$ The radiotherapy port is determined by the extent of the dural lesions and the presence of leptomeningeal involvement.

High-dose methotrexate is the most effective drug for parenchymal PCNSL, but it is unclear if it has a role in PDL, because most patients respond to radiotherapy alone. Furthermore, high-dose methotrexate in conjunction with cranial irradiation can be neurotoxic, leading to progressive leukoencephalopathy, especially in older patients. For patients with disease that was localized to the dura and responded to radiotherapy, chemotherapy is unnecessary. Standard chemotherapy regimens for non-Hodgkin lymphoma and anti-CD20 monoclonal antibodies ${ }^{28}$ are effective therapies for systemic MZL, but these regimens have not been studied in dural MZL. Moreover, limited data from a retrospective study of patients with nongastric MZL showed no clear advantage of systemic chemotherapy over radiotherapy or surgery. ${ }^{40}$ If the leptomeninges are involved, intrathecal chemotherapy or whole-brain radiotherapy is required.

\section{Conclusions}

Complete response is achieved in most patients, even in those with leptomeningeal spread of the disease, ${ }^{18,38}$ although nongastrointestinal MZL has a lower cure and higher relapse rate than gastrointestinal MZL. ${ }^{35}$ In one study, relapses were found in three of eight patients with PDL; all of the tumors were outside the CNS. ${ }^{18}$ Systemic recurrences can occur several years after the initial diagnosis of PDL. ${ }^{8}$ The dura is outside the blood-brain barrier, which may explain the increased risk of systemic relapse compared with other types of PCNSL. Therefore, continued follow up and clinical surveillance are recommended for all patients.

\section{References}

1. Abdel Aziz KM, van Loveren HR: Primary lymphoma of Meckel's cave mimicking trigeminal schwannoma: case report. Neurosurgery 44:859-862, 1999

2. Abdullah S, Morgensztern D, Rosado MF, Lossos IS: Primary lymphoblastic B-cell lymphoma of the cranial dura mater: a case report and review of the literature. Leuk Lymphoma 46: 1651-1657, 2005

3. Abrey LE, Batchelor TT, Ferreri AJ, Gospodarowicz M, Pulczynski EJ, Zucca E, et al: Report of an international workshop to standardize baseline evaluation and response criteria for primary CNS lymphoma. J Clin Oncol 23:5034-5043, 2005

4. Abrey LE, Yahalom J, DeAngelis LM: Treatment for primary
CNS lymphoma: the next step. J Clin Oncol 18:3144-3150, 2000

5. Altundag MK, Ozisik Y, Yalcin S, Akyol F, Uner A: Primary low grade B-cell lymphoma of the dura in an immunocompetent patient. J Exp Clin Cancer Res 19:249-251, 2000

6. Amaker BH, Ghatak NR, Jebraili SA, Ferreira-Gonzalez A, Kornstein MJ: Primary T-cell-rich B-cell lymphoma masquerading as a meningioma. Arch Pathol Lab Med 124: 1700-1703, 2000

7. Arcaini L, Paulli M, Boveri E, Vallisa D, Bernuzzi P, Orlandi $\mathrm{E}$, et al: Splenic and nodal marginal zone lymphomas are indolent disorders at high hepatitis $\mathrm{C}$ virus seroprevalence with distinct presenting features but similar morphologic and phenotypic profiles. Cancer 100:107-115, 2004

8. Assaf C, Coupland SE, Hummel M, Jahnke K, Mostafafivar S, Stein $\mathrm{H}$, et al: Relapse of primary extranodal marginal-zone Bcell lymphoma of the dura mater. Lancet Oncol 6:187-189, 2005

9. Benouaich A, Delord JP, Danjou M, Richaud J, Urocoste E, Soum F, et al: [Primary dural lymphoma: a report of two cases with review of the literature.] Rev Neurol (Paris) 159: 652-658, 2003 (Fr)

10. Beriwal S, Hou JS, Miyamoto C, Garcia-Young JA: Primary dural low grade BCL-2 negative follicular lymphoma: a case report. J Neurooncol 61:23-25, 2003

11. Bodi I, Hussain A, Gullan RW, Safa AS: January 2003:56-yearold female with right frontal tumor of the dura. Brain Pathol 13:417-418, 2003

12. Estevez M, Chu C, Pless M: Small B-cell lymphoma presenting as diffuse dural thickening with cranial neuropathies. J Neurooncol 59:243-247, 2002

13. Ferreri AJ, Guidoboni M, Ponzoni M, De Conciliis C, Dell'Oro $\mathrm{S}$, Fleischhauer K, et al: Evidence for an association between Chlamydia psittaci and ocular adnexal lymphomas. J Natl Cancer Inst 96:586-594, 2004

14. Freudenstein D, Bornemann A, Ernemann U, Boldt R, Duffner F: Intracranial malignant B-cell lymphoma of the dura. Clin Neuropathol 19:34-37, 2000

15. Goetz P, Lafuente J, Revesz T, Galloway M, Dogan A, Kitchen N: Primary low-grade B-cell lymphoma of mucosa-associated lymphoid tissue of the dura mimicking the presentation of an acute subdural hematoma. Case report and review of the literature. J Neurosurg 96:611-614, 2002

16. Hodgson D, David KM, Powell M, Holton JL, Pezzella F: Intracranial extracerebral follicular lymphoma mimicking a sphenoid wing meningioma. J Neurol Neurosurg Psychiatry 67: 251-252, 1999

17. Isaacson PG, Du MQ: MALT lymphoma: from morphology to molecules. Nature Rev Cancer 4:644-653, 2004

18. Iwamoto FM, DeAngelis LM, Abrey LE: Primary dural lymphomas: a clinicopathologic study of treatment and outcome in eight patients. Neurology 66:1763-1765, 2006

19. Jazy FK, Shehata WM, Tew JM, Meyer RL, Boss HH: Primary intracranial lymphoma of the dura. Arch Neurol 37:528-529, 1980

20. Johnson MD, Kinney MC, Scheithauer BW, Briley RJ, Hamilton K, McPherson WF, et al: Primary intracerebral Hodgkin's disease mimicking meningioma: case report. Neurosurgery 47:454-456, 2000

21. Johnson MD, Powell SZ, Boyer PJ, Weil RJ, Moots PL: Dural lesions mimicking meningiomas. Hum Pathol 33:1211-1226, 2002

22. Kambham N, Chang Y, Matsushima AY: Primary low-grade Bcell lymphoma of mucosa-associated lymphoid tissue (MALT) arising in dura. Clin Neuropathol 17:311-317, 1998

23. Kelley TW, Prayson RA, Barnett GH, Stevens GH, Cook JR, Hsi ED: Extranodal marginal zone B-cell lymphoma of mucosa-associated lymphoid tissue arising in the lateral ventricle. Leuk Lymphoma 46:1423-1427, 2005 
24. Kumar S, Kumar D, Kaldjian EP, Bauserman S, Raffeld M, Jaffe ES: Primary low-grade B-cell lymphoma of the dura: a mucosa associated lymphoid tissue-type lymphoma. Am J Surg Pathol 21:81-87, 1997

25. Lachance DH, O'Neill BP, Macdonald DR, Jaeckle KA, Witzig TE, Li CY, et al: Primary leptomeningeal lymphoma. Report of 9 cases, diagnosis with immunocytochemical analysis, and review of literature. Neurology 41:95-100, 1991

26. Lecuit M, Abachin E, Martin A, Poyart C, Pochart P, Suarez F, et al: Immunoproliferative small intestinal disease associated with Campylobacter jejuni. N Engl J Med 350:239-248, 2004

27. Lehman NL, Horoupian DS, Warnke RA, Sundram UN, Peterson K, Harsh GR IV: Dural marginal zone lymphoma with massive amyloid deposition: rare low-grade primary central nervous system B-cell lymphoma. Case report. J Neurosurg 96:368-372, 2002

28. Martinelli G, Laszlo D, Ferreri AJ, Pruneri G, Ponzoni M, Conconi A, et al: Clinical activity of rituximab in gastric marginal zone non-Hodgkin's lymphoma resistant to or not eligible for anti-Helicobacter pylori therapy. J Clin Oncol 23: 1979-1983, 2005

29. Miller M, Loffe V, Ruffin WK, Giri PG: Primary MALT lymphoma of the dura in a patient with active scleroderma. Clin Adv Hematol Oncol 2:815-819, 2004

30. Miranda RN, Glantz LK, Myint MA, Levy N, Jackson CL, Rhodes CH, et al: Stage IE non-Hodgkin's lymphoma arising from the dura: a clinicopathologic study of five cases. Arch Pathol Lab Med 120:254-260, 1996

31. Nguyen D, Nathwani BN: Primary meningeal small lymphocytic lymphoma. Am J Surg Pathol 13:67-70, 1989

32. Rottnek M, Strauchen J, Moore F, Morgello S: Primary dural mucosa-associated lymphoid tissue-type lymphoma: case report and review of the literature. J Neurooncol 68:19-23, 2004

33. Sanjeevi A, Krishnan J, Bailey PR, Catlett J: Extranodal marginal zone B-cell lymphoma of malt type involving the cavernous sinus. Leuk Lymphoma 42:1133-1137, 2001
34. Scott TF, Hogan EL, Carter TD, Garen PD, Brillman J, Kurent JE: Primary intracranial meningeal lymphoma. Am J Med 89: 536-538, 1990

35. Thieblemont C, Bastion Y, Berger F, Rieux C, Salles G, Dumontet $\mathrm{C}$, et al: Mucosa-associated lymphoid tissue gastrointestinal and nongastrointestinal lymphoma behavior: analysis of 108 patients. J Clin Oncol 15:1624-1630, 1997

36. Thieblemont C, Berger F, Dumontet C, Moullet I, Bouafia F, Felman P, et al: Mucosa-associated lymphoid tissue lymphoma is a disseminated disease in one third of 158 patients analyzed. Blood 95:802-806, 2000

37. Tsang RW, Gospodarowicz MK, Pintilie M, Wells W, Hodgson DC, Sun A, et al: Localized mucosa-associated lymphoid tissue lymphoma treated with radiation therapy has excellent clinical outcome. J Clin Oncol 21:4157-4164, 2003

38. Tu PH, Giannini C, Judkins AR, Schwalb JM, Burack R, O'Neill BP, et al: Clinicopathologic and genetic profile of intracranial marginal zone lymphoma: a primary low-grade CNS lymphoma that mimics meningioma. J Clin Oncol 23: 5718-5727, 2005

39. Zinzani PL, Magagnoli M, Galieni P, Martelli M, Poletti V, Zaja F, et al: Nongastrointestinal low-grade mucosa-associated lymphoid tissue lymphoma: analysis of 75 patients. J Clin Oncol 17:1254-1258, 1999

40. Zucca E, Conconi A, Pedrinis E, Cortelazzo S, Motta T, Gospodarowicz MK, et al: Nongastric marginal zone B-cell lymphoma of mucosa-associated lymphoid tissue. Blood 101: 2489-2495, 2003

Manuscript received July 15, 2006.

Accepted in final form October 4, 2006.

Address reprint requests to: Lauren E. Abrey, M.D, Department of Neurology, Memorial Sloan-Kettering Cancer Center, 1275 York Avenue, New York, New York 10021. email: abreyl@mskcc.org. 